\title{
Perception of Adolescents on the Attitudes of Providers on Their Access and Use of Reproductive Health Services in Delta State, Nigeria
}

\author{
Andrew G. Onokerhoraye, Johnson Egbemudia Dudu* \\ Centre for Population and Environmental Development, Benin City, Nigeria \\ Email: *jedudu@yahoo.co.uk
}

How to cite this paper: Onokerhoraye, A.G. and Dudu, J.E. (2017) Perception of Adolescents on the Attitudes of Providers on Their Access and Use of Reproductive Health Services in Delta State, Nigeria. Health, 9, 88-105.

http://dx.doi.org/10.4236/health.2017.91007

Received: November 2, 2016

Accepted: January 10, 2017

Published: January 13, 2017

Copyright ( 92017 by authors and Scientific Research Publishing Inc. This work is licensed under the Creative Commons Attribution International License (CC BY 4.0).

http://creativecommons.org/licenses/by/4.0/

(c) (i) Open Access

\begin{abstract}
This paper examines the perception of adolescents on the attitudes of providers on their access and use of reproductive health services (ARHS) in Delta State, Nigeria, with a view of assessing the impact of providers' attitude on the use of adolescents' reproductive health services in Delta State. The study adopted a survey design to collect primary data using questionnaires and focus group discussions (FGDs) from adolescents in a sample of schools. A sample size of 1500 respondents was taken from 12 schools in six Local Government Areas in three Senatorial Districts in Delta State, Nigeria. The locations of the schools were such that six each were in rural and urban communities respectively. The result from the study was that unfriendly attitudes of providers which keep adolescents waiting, inadequate duration of consultations, judgmental attitudes of some providers, lack of satisfactory services provision and lack of confidentiality will put off adolescents from accessing and using adolescents' reproductive health services irrespective of their sex, age, class, religion, residence, ethnic group, parents' education or income levels. The paper concludes that medical personnel take all these issues very seriously when dealing with adolescents to enhance access and use adolescents' reproductive health services in Delta State and indeed Nigeria.
\end{abstract}

\section{Keywords}

Providers Attitudes, Adolescents, Reproductive Health, Delta State, Nigeria

\section{Introduction}

Adolescents' Reproductive Health Services (ARHS) is concerned with the constellation of methods, techniques and services that contribute to reproductive 
and sexual health and wellbeing by preventing and solving reproductive health problems of adolescents. It also includes sexual health, the purpose of which is the enhancement of life and personal relations and not merely counseling and care related to reproduction and sexually transmitted diseases [1]. Adolescence represents a unique transition during which teenagers take on new responsibilities of taking care of themselves and seeking health care. This population may not be socialized into the health care system and may have incorrect beliefs that influence their view of reproductive health. Many of the avoidable problems in reproductive health $(\mathrm{RH})$, such as unwanted pregnancy, abortion and its complications, sexually transmitted infections (STIs) including the acquired immunodeficiency syndrome (AIDS) take place during this stage of the lifespan. These challenges are as a result of many factors among which are the lack of access and utilization of services by adolescents; hence there have been concerns about adolescents' reproductive health [2]. One of the major issues in adolescents' lack of access and use of reproductive health services is providers' attitude. Different aspects of providers attitude affect adolescents' uptake and usage of reproductive health services such as: how much the clients are kept waiting when they visit providers, the satisfaction with providers services; how much time they spend in rendering services to their clients, the level of confidentiality the providers observe when working with clients, how effective a physician is in his work, the assessment whether their clients are judge by them, and whether adolescents treatment required parental notification [3] [4] [5] [6]. Hence, it is the goal of the paper to examine the perception of adolescents on the attitudes of providers on their access and use of reproductive health services in Delta State, Nigeria with a view of assessing the impact of providers' attitudes on their access and use of ARHS in Delta State by seeking the perception adolescents who use or may use such reproductive health services.

\section{Background to the Study}

Adolescent age is a period when the influence of peers and the social environment is strong and contributes significantly to the attitudes and sexual behavior of young people [2] [7]. Adolescence is the most difficult stage in life; where youth try new things including sexual activities [8]. All over the world, adolescents are seen as vulnerable group due to the nature of this stage of growth in the life cycle [9] [10] [11] [12]. Adolescence is a time of major transition between childhood and adulthood. It is a period when significant physical, psychological, and behavioral changes occur and when young people develop many of the habits, behaviors, and relationships they will carry into their adult lives [13]. Globally, this is a period that has unique potentials for new sexual ideas, experiences and opportunities that affect the behavior of youth. The period of adolescence is plagued by vulnerabilities to biological and socio-cultural problems, lack of adequate health information and services, inadequate life building skills and lack of access and utilization of reproductive health services [11].

A Plethora of attitudinal issues are related to attempts by adolescents to either 
access or use reproductive health services. The effectiveness of physicians had been adduced as a reason why adolescents may or may not seek health care. Adolescents, who believed physicians were more effective, were more likely to intend to seek care. Additionally, need factors such as whether adolescent seeking treatment are being judged by health professionals to have significant health needs are least likely to use health care [3] [4]. According to research with youth, the most important barrier to care relates to provider attitudes that contraceptive services are inappropriate for young people [5]. Providers with this attitude frequently fail to take seriously youth's need for services and may even try to dissuade young people from having sexual relations. Providers' attitudes often reflect the tremendous difficulty that societies and cultures have in accepting the sexuality of adolescents and in viewing sexuality as a natural and positive part of the full development of every person. Such hostile attitudes may result in young people's giving up-not on having sexual intercourse-but on using contraception [6] [14]. An aspect of provider attitude is the waiting time and duration of services in most health Centers which keep patients for hours without being attended to. This has led to many patients especially adolescents from coming to such health facilities and using the services in them [6] [12] [14] [15].

Another aspect of providers' attitude which may either encourage or discourage adolescents from accessing and using adolescents' reproductive health services is how much their providers are confidential about their treatments. A host of studies have identified confidentiality as key to adolescent use or non-use of ARHS [12] [16] [17] [18] [19]. Hock-Long et al. [19] in their study identified confidentiality of consent for care and service environment as two types of structural factors which affect access to sexual and reproductive health services. Ralpha \& Brindis [15] believed confidentiality protections are particularly important for reproductive and other sensitive healthcare, as adolescents are likely to forgo needed care in the absence of these protections. Giving tips on how to achieve confidentiality, they opined that adolescents needed to have time alone with their providers, but this has not been the case with most physicians. The consequences are that, adolescents have refused to use the services of such health facilities. Kanthiti [10] review of factors necessary for effective adolescent reproductive health services in Africa, Asia and Latin America revealed that confidentiality and privacy were the most important pull factors. For example, out of the five studies in Africa, four of them (80\%) indicated that confidentiality and privacy were important to adolescents since, they would feel comfortable to discuss their problems when there is confidentiality and privacy with their providers, according to the study, sadly, some physicians have not taken issue of confidentiality seriously, thereby leading to low patronage by adolescents of their services.

A common fear that adolescents often have is that of parental notification through providers' communications or that service provider will tell their parents that they came to the clinic for reproductive health care. Young people would feel confident that their important and sensitive concerns will not be re- 
vealed to other people or their parents will continue to come for the services otherwise, in the event they feel their parents or love ones will be told about their RH situation, they may not use such providers due to lack of privacy and confidentiality [8] [20] [21] [22]. Fear of disclosure inhibits the sexually active adolescents especially female from seeking contraception and other reproductive health services [23]. As a result, adolescents do not use family planning or reproductive health services. Guttmacher Institute [24] also found parental control to be significant in the usage or non-usage of adolescent reproductive health. This came up because when youths visited the health facilities, they were asked for parental approval and this worked against some adolescents taking up the services. Berkat \& Murtaza [25] and Kamau [9] recommended that parents and communities need to be persuaded to support adolescents' reproductive health initiatives if the chances of access and use of such services are to improved.

\section{Methods}

\subsection{Reconnaissance Survey and Delimitation of the Studied Area}

Reconnaissance visits were paid to the surveyed Local Government Areas (LGAs). The LGAs were: Burutu and Bomadi-Delta South Senatorial District, Ughelli North and Udu-Delta Central Senatorial District and Ika South and Ukwuani-Delta North Senatorial District). These were followed by contacts setting, acquisition of necessary clearance and authorization from the Ministry of Basic Education, Delta State, which is the body responsible for Secondary Education. Another aim of the contacts setting was to make appointments for data collection.

\subsection{Research Design and Population}

The survey design was adopted for this study due its nature. The data needed were primary data using questionnaires, in-depth interviews and focus group discussions (FGDs). Adolescents in schools were the focus of this study. This was in recognition of the fact that adolescents spend most of their time in schools and undergo adolescence development and transition during their school life. It is also in schools that adolescents have close interaction with their peers who may influence their sexual health behavior. The schools are thus critical in shaping reproductive and sexual behavior of adolescents, and in providing reproductive health information and services that can help them meet their reproductive and other health concerns [9]. The study populations were adolescents in public secondary schools in Delta State. The total population of students in these schools was 218,562 [26]. The reason for the selection of students in secondary schools as participants for this study is based on the fact that the students are likely to have the age range of $10-20$ as defined as adolescents for the purpose of this study.

\subsection{Data Collection: Quantitative Data}

In this study, combinations of sampling techniques were used at different stages. 
In the first stage, the cluster sampling technique was used in selecting the Local Government Areas (LGAs) and the schools in the LGAs where this research was carried out. The use of cluster sampling was due to concentration of youth in the selected LGAs and schools with similar attributes [27]. Before the selection of LGAs, Delta State was demarcated into three parts based on existing senatorial districts. Two LGAs were selected from each senatorial district; making a total number of six LGAs. In each LGA, two secondary schools were selected purposively which included a school in an urban area and one school from a rural location; bringing the total schools where the study was carried out to 12 from a pool of 452 secondary schools [26]. The sample size was 1500 students and this was equally drawn from the twelve schools with each having 125 respondents respectively. The selection of 125 students from each class was based on the fact that equal sample of students were drawn from each class for equal representation of students in each school. The sample size of 1500 was drawn using the Rule of Thumb which states that; for large populations (over 150,000), small sampling ratios (1 percent) are possible and sample of about 1500 can be very accurate [28]. In the second stage, the stratified sampling technique was used in order to ensure equal opportunity of participation of students (males and females). The study used systematic random sampling to select respondents from each school-125 secondary students comprising 63 male and 62 females, since the population of males was higher in most classes.

The questions for the study were drawn from existing studies on access and use of ARHS by adolescents in Nigeria. The questionnaire comprised of two sections. Part " $\mathrm{A}$ " is made up socio-demographic and economic characteristics of respondents such as: sex, class, age, religion, ethnicity, residual location and their parents' level of education and income. In order to find perceptions of adolescents to attitudes of providers and how they affect their access and use of ARHS, the study relied on part "B" of the questionnaire where respondents were interrogated on their comfort level to waiting time for ARHS providers before receiving services; satisfaction with the duration of the services they eventually received after waiting; overall satisfaction with the ARHS they have received from providers; willingness to use ARHS in the presence of a third party and view on the unfriendly attitudes of medical person. The questionnaires consisted of simple questions requiring "Yes" or "No" answers on hand and a likert scale questions ranging from strongly agreed to strongly disagree. The questionnaire was first pilot-tested in one secondary school and appropriately revised by authors before coming out with the final questionnaire that was used for this study.

\subsection{Data Collection: Qualitative Data}

Six focus group discussions (FGDs)-three for males and three for females were held in the three senatorial districts with 12 students each (6 males and 6 females) from each senatorial district to complement data from survey. In all, two FGDs were held per Senatorial District with one for males and the other for females. In all the 12 schools were the study was conducted, the best students in 
either integrated science or biology in classes were selected to take part in the FGDs depending on whether they were senior or junior schools. The selection of either biology or integrated science was due to their subject of reproductive health. In the school, a balloting was first introduced to select either a male student or a female best student, since six schools were allotted male slots while some got female slots. This allowed for equal participation of equal number of male as well as female FGDs-36 persons each who took part in three FGDs. Three focus group discussions for males were conducted by the two authors who had versed experiences in the use of this tool for data collection over time. The other three focus group discussions were conducted by female research officers of Centre for Population and Environmental Development with excellent knowledge of FGDs. In both male and female focus group discussion sessions, one of the persons involved took care of the tape recorder and note taking while the other was responsible for facilitating the discussions. A focus group discussion guide was used to itemize questions on: barriers to effective access and use of ARHS by adolescents; significance of prompt ARHS to access and use of RH by adolescents; effects of long waiting time at ARHS clinics; confidentiality and access/use of ARHS by adolescents and medical personnel attitudes that are unfriendly and ARHS provision to adolescents. All, the questions were also pilot-tested to avoid ambiguities. The FGDs were held in six of the schools were the study took place in a serene environment devoid of noise. Each session was held for an average of 58 minutes.

\subsection{Data Analysis}

The Statistical Products and Service Solutions (SPSS) by IBM, version 21 was used for data analysis in this study-analyzing 1465 filled questionnaires-with 35 questionnaires declared invalid of 1500 administered in this study. Thus, the analysis was based on 1465 questionnaires. First, the analysis involved the use of descriptive statistics such as frequency tables, percentages to elucidate respondents' demographic characteristics. Cross tabulation was used to analyze adolescents' perception of providers attitude using variables such as waiting time, duration of services, satisfaction with services and the relationship between demographic/economic characteristics and attitude. N6 NUD*IST software was used to analyze qualitative data after transcription and coded by themes relevant to the study.

\subsection{Ethical Considerations}

As a study that dealt with minors and in line with the Centre for Population and Environmental Development standards, some ethical guidelines were followed. Necessary authorizations and clearance before commencement of the study was obtained from relevance authorities. Although parental or guardian consent was required in the course of undertaking this research with minors, this was not necessary because the target of this study was the in-school adolescents. The researchers considered the Ministry of Basic Education as well as the school au- 
thorities as the guardians. In Nigeria, once, the students were in school, the school authorities take over the role of guardians and decide on what is best for their students within government approved boundaries. The approval of this study by CPED's ethics committee was also predicated on this belief of students' ownership by the school authority once in schools premises. However, Informal and verbal consents were obtained from the adolescents before the commencement of the survey and interviews [9]. The researchers also informed the target group in detail about the study purpose and were made to be aware that participation was voluntary, and that they will be free to decline or end the participation or interviews at any time if they have compelling reasons to do so. The target groups were also informed that the survey will be confidential and that the FGDs would be held with confidentiality, and that it would not be used for any other purpose other than for academic purposes. The FGDs took place in situations that enhanced confidentiality and which was comfortable for the researcher and adolescents [9] [29] [30]. This enhanced participant's sensitivity and cooperation [31].

\section{Results and Discussions}

The socio-demographic and economic characteristics of the respondents are presented in Table 1. From the table, it is evidence that the study comprised of $51.3 \%$ of male and $48.3 \%$ female of which $49.7 \%$ of them were in Junior Secondary Schools and $50.3 \%$ of them who were from Senior Secondary Schools. The respondents were made up of $37.5 \%$ who fell between the ages of 15 - 17 years, $36.2 \%$ whose ages were $12-14$ years, $21.5 \%$ of them were from ages $9-11$ years. In terms of religion denominations, the respondents were from protestant, Pentecostal and catholic worships with $42 \%, 40.6 \%$ and $15.4 \%$ respectively. By the ethnic origin of the respondents, almost equal percentages were found in Ijaw, Urhobo and Igbo with $28.5 \%, 28.3 \%$ and $28.1 \%$. Regarding the educational level of respondents' parents, $32.9 \%$ of them completed secondary school, $32 \%$ of them completed primary school, and $25.8 \%$ had no schooling while $9.3 \%$ of them attended one form of tertiary education or the others. Evidence from the table also showed that $34.8 \%$ of the respondents do not know the income level of their parents, $28.7 \%$ of the parents earned $\mathrm{N} 10,000$ or less, $14 \%$ of parents were found to be in the income bracket of N11,000 - N20,000, 12.2\% of parents earned $\mathrm{N} 21,000-\mathrm{N} 30,000,6.2 \%$ of the parents also earned N41,000 and above and $4 \%$ of the respondents' parents earned N31,000 - N40,000. The participants in the FGDs included 72 adolescents in school, made up of 36 males and $36 \mathrm{fe}-$ males with ages ranging from 11 to 18 years. The participants were also made up of 36 adolescents each from junior (Integrated science Students) and senior (Biology Students) secondary schools respectively.

\subsection{Waiting Time in Adolescents Clinic and the Comfort Level of Service Users in the Studied Area}

Respondents in this study were asked whether they were comfortable with the 
Table 1. Socio-demographic and economic characteristics of the sampled population (1465).

\begin{tabular}{|c|c|c|}
\hline Variable & No & $\%$ \\
\hline \multicolumn{3}{|l|}{ Sex } \\
\hline Male & 752 & 51.3 \\
\hline Female & 713 & 48.7 \\
\hline \multicolumn{3}{|l|}{ Classes of Students } \\
\hline Junior Sec. Students & 731 & 49.7 \\
\hline Senior Sec. Students & 734 & 50.3 \\
\hline \multicolumn{3}{|l|}{ Age (Year) } \\
\hline $9-11$ & 315 & 21.5 \\
\hline $12-14$ & 530 & 36.2 \\
\hline $15-17$ & 550 & 37.5 \\
\hline $18-20$ & 70 & 4.8 \\
\hline \multicolumn{3}{|l|}{ Religion } \\
\hline Catholic & 226 & 15.4 \\
\hline Protestant & 616 & 42.1 \\
\hline Pentecostal & 595 & 40.6 \\
\hline Others & 28 & 1.9 \\
\hline \multicolumn{3}{|l|}{ Ethnicity } \\
\hline Igbo & 411 & 28.1 \\
\hline Isoko & 118 & 8.6 \\
\hline Ijaw & 418 & 28.5 \\
\hline Urhobo & 430 & 28.3 \\
\hline Itsekiri & 19 & 1.3 \\
\hline Others & 69 & 5.2 \\
\hline \multicolumn{3}{|l|}{ Parents' Highest Level of Education } \\
\hline No schooling & 377 & 25.8 \\
\hline Completed Primary School & 469 & 32.0 \\
\hline Completed Secondary School & 483 & 32.9 \\
\hline Tertiary education and equivalents & 136 & 9.3 \\
\hline \multicolumn{3}{|l|}{ Parents' Income } \\
\hline 10,000 or less & 421 & 28.7 \\
\hline $11,000-20,000$ & 205 & 14.0 \\
\hline $21,000-30,000$ & 179 & 12.2 \\
\hline $31,000-40,000$ & 59 & 4.0 \\
\hline 41,000 and above & 91 & 6.2 \\
\hline I don't know & 510 & 34.8 \\
\hline \multicolumn{3}{|l|}{ Residence } \\
\hline Rural & 726 & 49.6 \\
\hline Urban & 739 & 50.4 \\
\hline
\end{tabular}


waiting time in medical places they went to seek for ARHS more recently. Figure 1 shows that an average of $66.8 \%$ was not comfortable with the waiting time in the studied area. The highest proportion of respondents who were not comfortable with the waiting time was in Bomadi LGA with $88.8 \%$. Others were 69.4\% in Ukwuani, 67.6\% in Ika South LGA, 67.3\% in Burutu LGA, $62.8 \%$ in Udu LGA and $54.6 \%$ in Ughelli North-thus establishing that respondents in the study area were not happy with waiting time before seeing a provider and with the attitude of health workers who keep them waiting when they visit the health centers. Therefore, adolescents who were not comfortable with the waiting time might have issue with the accessing and using the reproductive health services in the health facilities they visited especially if they perceive their situation not to be so severe and forgo the use of such services [32] [33] [34]. According to Adelman et al. [32], once adolescents perceived themselves as healthy, they may forgo the services they are supposed to access and utilize if any barrier like waiting time is placed before them as the excerpt below reveals from a female FGD participant in Delta Central:

"Waiting for a long time in health centre because of coming late of doctor, I believed is a big challenge to get treatment. I for one do not like it. I am sure most persons do not also like it like me. If we keep experiencing this, it will make us not to use the clinic. This one is a big problem".

\subsection{Adolescents' Satisfaction with Adolescents Reproductive Health Services Received from Providers}

The ultimate goal of every reproductive health service received is to be satisfied, as defined by certain parameters. In adolescents' reproductive health, satisfaction is defined by meeting the reproductive health of the adolescents in question. It is from this perspective that the respondents were asked of their satisfaction with the ARHS they have received from providers. Table 2 summarizes the answers to the questions by respondents based on the number of respondents that have used reproductive health services as at the time of the study (1035). In the six surveyed LGAs, a greater proportion of the respondents (61.8\%) were not satisfied with the reproductive health services they received the last time they went for ARHS. There were some variations from one LGA to the others. The highest

\section{Comfort level of waiting time}

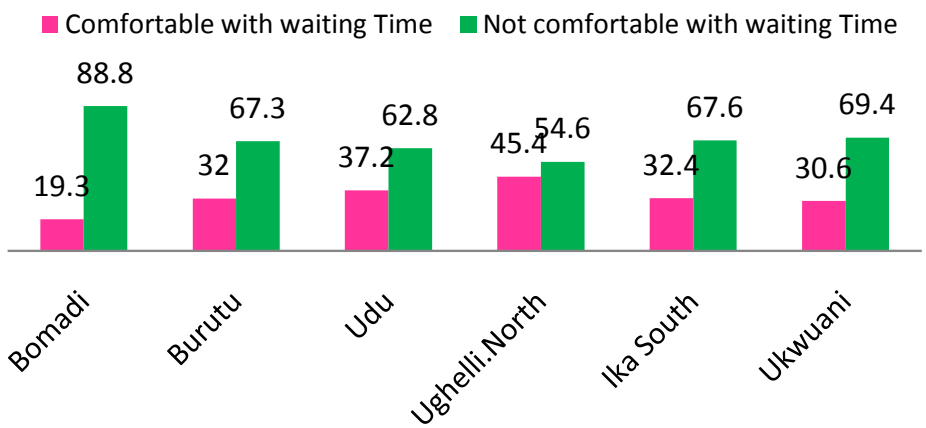

Figure 1. Waiting time and comfort level of ARHS seekers (LGAs). 
Table 2. Satisfaction with providers adolescents reproductive health services in the studied LGAs.

\begin{tabular}{ccccccc}
\hline & \multicolumn{3}{c}{ Satisfaction with ARHS } & \multicolumn{2}{c}{ Total } \\
\cline { 2 - 5 } LGAs & \multicolumn{3}{c}{ Satisfaction with ARHS } & \multicolumn{2}{c}{$\begin{array}{c}\text { Do not Satisfy with } \\
\text { ARHS }\end{array}$} & \multicolumn{2}{c}{} \\
\cline { 2 - 5 } & N & $\%$ & N & $\%$ & N & $\%$ \\
\hline Bomadi & 40 & 24.8 & 121 & 75.1 & 161 & 100 \\
Burutu & 54 & 36.7 & 93 & 63.2 & 147 & 100 \\
Udu & 72 & 40.0 & 108 & 60.0 & 180 & 100 \\
Ughelli. & 97 & 52.4 & 88 & 47.6 & 185 & 100 \\
North & 70 & 39.1 & 109 & 60.9 & 179 & 100 \\
Ika South & 62 & 33.9 & 121 & 66.1 & 183 & 100 \\
Ukwuani & 395 & 38.2 & 640 & 61.8 & 1035 & 100 \\
Total & & & & & &
\end{tabular}

proportion of respondents $(75.1 \%)$ who were not satisfied with the services provided was in Bomadi LGA. This was followed by Ukwuani (66.1\%), Burutu LGA with $63.2 \%$, Ika South and Udu LGA with $60.9 \%$ and $60 \%$ respectively. It was only in Ughelli North LGA that the lowest proportion of $47.6 \%$ was recorded. This may be due to the individual experiences when they visited the healthcare facilities in their LGAs. That most respondents were dissatisfied with the services is an indication of the challenges which may restrict access and use of such services occasioned by the length of time they spent in the locations where they received services which might be connected to attitudes of the providers. This finding agrees with those of Brown and Guthrie [6] and Coyne-Beasley et al. [33] who in their separate studies observed that lack of use of adolescents' reproductive health services was connected with their dissatisfactions with the services provided by the medical personnel as the extract from the male Focus Group Discussion in one of the schools show:

"Why should I go back to get treatment from a doctor or a nurse who could not treat me well. Most of the persons attending to us are very judgmental. I have not been satisfied with the services of most of the medical persons because of this attitude. I have to look for alternatives each time I meet these kinds of personnep'.

\subsection{Adolescents' Satisfaction with Duration of ARHS Services}

Table 3 shows that the clients were not satisfied with the time the medical personnel spent with them. In the six surveyed LGAs, over $62 \%$ of the respondents (1035 who used ARHS) were of the opinion that they were not satisfied with the time the medical personnel spent with them. In the individual LGAs, Bomadi LGA recorded the highest proportion (75.2\%) of respondents who were dissatisfied with the time the medical personnel spent with them. Bomadi LGA was followed by Burutu and Ukwuani LGAs with $66.9 \%$ and $66.1 \%$ respectively. Other LGAs in this category were Udu and Ika South with $62.2 \%$ and $62 \%$ respectively 
Table 3. Satisfaction with medical personnel duration of services in the studied LGAs.

\begin{tabular}{|c|c|c|c|c|c|c|}
\hline \multirow{3}{*}{ LGAs } & \multicolumn{4}{|c|}{$\begin{array}{l}\text { Satisfaction with Medical Personnel } \\
\text { duration of Services }\end{array}$} & \multirow[b]{3}{*}{$\mathbf{N}$} & \multirow[b]{3}{*}{$\%$} \\
\hline & \multicolumn{2}{|c|}{$\begin{array}{l}\text { Satisfy with duration } \\
\text { of Services }\end{array}$} & \multicolumn{2}{|c|}{$\begin{array}{l}\text { Not Satisfy with } \\
\text { duration of Services }\end{array}$} & & \\
\hline & $\mathbf{N}$ & $\%$ & $\mathbf{N}$ & $\%$ & & \\
\hline Bomadi & 40 & 24.8 & 121 & 75.2 & 161 & 100 \\
\hline Burutu & 50 & 34.0 & 97 & 66.9 & 147 & 100 \\
\hline Udu & 68 & 37.8 & 112 & 62.2 & 180 & 100 \\
\hline Ughelli.North & 96 & 51.9 & 89 & 48.1 & 185 & 100 \\
\hline Ika South & 68 & 38.0 & 111 & 62.0 & 179 & 100 \\
\hline Ukwuani & 62 & 33.9 & 121 & 66.1 & 183 & 100 \\
\hline Total & 384 & 37.1 & 651 & 62.9 & 1035 & 100 \\
\hline
\end{tabular}

and Ughelli North LGA with 48.1\%. A close observation of the respondents' discomfort with waiting time, their dissatisfaction with the services they received and dissatisfaction with providers' duration of services in this study corroborate earlier studies results that equally showed adolescents dissatisfaction with services they received due to providers attitudes [12] [14] [15]. The statement from a female FGD equally revealed the dissatisfaction with duration of services as reported:

"Most medical providers are full of themselves. You can imagine my own experience. After waiting for over 2 hours, he only took 5 minutes to talk to me and calling in the next person without doing proper examination on me. This is what happens all the time you visit for consultations".

\subsection{Providers Attitudes and Confidentiality of Adolescents' Service}

One of the issues relating to providers' attitudes is confidentiality of services which may be observed or not depending on the providers. In this study, respondents (All 1465 participants) were asked if they would be willing to use ARHS in the presence of a third party by allowing them to be in their rooms of services. Table 4 indicates that a vast proportion of the respondents disagreed with the statement that they would be willing to be attended to in the presence of other persons. Though some proportion of respondents in the studied area (15.9\%) revealed that they will not mind to be attended to in the presence of others, $84.1 \%$ of respondents in the six LGAs were of the opinion that they will be concerned. This was an overwhelming decision in all the six LGAs, thus revealing the importance of confidentiality in the health seeking behaviors of teenagers. Thus any services provided without confidentiality most likely will not be used by adolescents in Delta State. Hence this study agrees with what Millstein [35]; Ralpha \& Brindis [15] and Isiugo-Abanihe [36] who in their separate studies found out that lack of confidentiality will hinder the ability to disclose 
Table 4. Respondents tolerance for a third party during services in the studied LGAs.

\begin{tabular}{|c|c|c|c|c|c|c|c|c|c|c|}
\hline \multirow{3}{*}{ LGAs } & \multicolumn{8}{|c|}{$\begin{array}{c}\text { ARHS Seekers and tolerance for a third Party } \\
\text { during services }\end{array}$} & \multirow{2}{*}{\multicolumn{2}{|c|}{ Total }} \\
\hline & \multicolumn{2}{|c|}{$\begin{array}{l}\text { Strongly } \\
\text { Agreed }\end{array}$} & \multicolumn{2}{|c|}{ Agreed } & \multicolumn{2}{|c|}{ Disagreed } & \multicolumn{2}{|c|}{$\begin{array}{l}\text { Strongly } \\
\text { Disagreed }\end{array}$} & & \\
\hline & $\mathbf{N}$ & $\%$ & $\mathbf{N}$ & $\%$ & $\mathbf{N}$ & $\%$ & $\mathrm{~N}$ & $\%$ & $\mathbf{N}$ & $\%$ \\
\hline Bomadi & 27 & $\begin{array}{c}11 . \\
1\end{array}$ & 18 & 7.4 & 174 & 71.3 & 25 & 10.2 & 244 & 100 \\
\hline Burutu & 14 & 5.8 & 18 & 7.4 & 174 & 71.6 & 37 & 15.2 & 243 & 100 \\
\hline Udu & 17 & 7.0 & 20 & 8.3 & 165 & 68.2 & 40 & 16.5 & 242 & 100 \\
\hline $\begin{array}{l}\text { Ughelli. } \\
\text { North }\end{array}$ & 20 & 8.2 & 22 & 9.0 & 164 & 67.2 & 38 & 15.6 & 244 & 100 \\
\hline Ika South & 23 & 9.3 & 15 & 6.1 & 159 & 64.6 & 49 & 19.9 & 246 & 100 \\
\hline Ukwuani & 23 & 9.3 & 16 & 6.5 & 170 & 69.1 & 37 & 15.0 & 246 & 100 \\
\hline Total & 124 & 8.5 & 109 & 7.4 & 1006 & 68.7 & 226 & 15.4 & 1465 & 100 \\
\hline
\end{tabular}

sensitive reproductive health information. According to them in their studies, in order to ensure adolescents' willingness to access health services, disclose sensitive health information, and return for necessary follow-up care, there must be confidentiality of ARHS. Therefore, providers who undermined the place of confidentiality in the provision of ARHS to Adolescents might make them not forgo not having sex but in the use of ARHS services as the statement from a male FGD revealed:

"Each time I go out to consult a medical person, this should be my personal affair with the medical personnel. He should be the one to keep my secret. However, most times, this had not been the case. If my health situation is exposed to anybody including my parents, I will not be using such health personnel because I desire some privacy in my life. Nobody is supposed to know what my health condition is, unless I volunteered to make it so".

\subsection{Importance of Medical Personnel Attitude in Access and Use of Adolescents' Reproductive Health Services in Delta State}

In order to explore the place of providers' attitudes in adolescents' access and use of ARHS, a direct question relating to provider attitude was asked (to all 1465 respondents who took part in the survey), if Medical personnel unfriendly attitude will not discourage them from using adolescents' reproductive health services? Table 5 contains the answers to the question. Across the six LGAs in the study area, $81.7 \%$ of respondents were of the opinion that providers attitudes will discourage them from using ARHS since they disagreed with the statement that unfriendly attitude of providers will not discourage them. In the LGAs, more respondents disagreed with the statement in Bomadi LGA (86\%), followed by $82.6 \%$ in Ukwuani LGA, $82.2 \%$ in Udu, $81.1 \%$ in Ughelli North LGA, $79.3 \%$ in Ika South LGA and 79.1\% in Burutu LGA. Thus provider attitude is significant to adolescent access and use of ARHS. The findings from this study agree 
Table 5. Medical personnel attitude and the use of ARHS.

\begin{tabular}{|c|c|c|c|c|c|c|c|c|c|c|}
\hline \multirow{3}{*}{ LGAs } & \multicolumn{8}{|c|}{ Medical Personnel Attitude and the Use of ARHS } & \multirow{2}{*}{\multicolumn{2}{|c|}{ Total }} \\
\hline & \multicolumn{2}{|c|}{$\begin{array}{c}\text { Strongly } \\
\text { Agreed }\end{array}$} & \multicolumn{2}{|c|}{ Agreed } & \multicolumn{2}{|c|}{ Disagreed } & \multicolumn{2}{|c|}{$\begin{array}{c}\text { Strongly } \\
\text { disagreed }\end{array}$} & & \\
\hline & $\mathbf{N}$ & $\%$ & $\mathbf{N}$ & $\%$ & $\mathbf{N}$ & $\%$ & $\mathbf{N}$ & $\%$ & $\mathrm{~N}$ & $\%$ \\
\hline Bomadi & 16 & 6.6 & 18 & 7.4 & 45 & 18.4 & 165 & 67.6 & 244 & 100 \\
\hline Burutu & 15 & 6.2 & 36 & 14.8 & 48 & 19.8 & 144 & 59.3 & 243 & 100 \\
\hline Udu & 16 & 6.6 & 27 & 11.2 & 47 & 19.4 & 152 & 62.8 & 242 & 100 \\
\hline $\begin{array}{l}\text { Ughelli } \\
\text { North }\end{array}$ & 17 & 7.0 & 29 & 11.9 & 44 & 18.0 & 154 & 63.1 & 244 & 100 \\
\hline Ika South & 17 & 6.9 & 34 & 13.8 & 55 & 22.4 & 140 & 56.9 & 246 & 100 \\
\hline Ukwuani & 18 & 7.3 & 25 & 10.2 & 54 & 22.0 & 149 & 60.6 & 246 & 100 \\
\hline Total & 99 & 6.8 & 169 & 11.5 & 293 & 20.0 & 904 & 61.7 & 1465 & 100 \\
\hline
\end{tabular}

with previous studies that providers' attitudes will affect the rate of access and utilization of ARHS. According to the studies, providers with repulsive attitudes frequently fail to take seriously youth's need for services and may even try to dissuade young people from having sexual relations. Providers' attitudes according to the studies often reflect the tremendous difficulty that societies and cultures have in accepting the sexuality of adolescents and in viewing sexuality as a natural and positive part of the full development of every person. Such hostile attitudes from the perspectives of the studies, may result in young people's giving up-not on having sexual intercourse-but on using contraception and other ARHS [6] [12] [14] [15]. The portion of female focus group discussion supports the point:

"Negative attitudes of doctors and nurses have not worked well in our hospitals. Some of them always abuse us girls. To them we are spoilt and do not know we should be treated well to receive health care. Most us preferred not taking treatment from such doctors and nurses".

\subsection{Relationship between Some Demographic Variables and Providers Attitudes to Adolescents' Reproductive Health Services}

Another issue examined relates to medical personnel unfriendly attitude and its effects on adolescents' reproductive health services looking at various demographic variables. The respondents were asked to agree or disagree with the statement "Medical personnel unfriendly attitudes will not discourage me from using adolescents' reproductive health services". Table 6 shows $82.3 \%$ and $81.1 \%$ of male and female respectively of respondents were of the view that unfriendly attitudes of providers will discourage them from using adolescents' reproductive health services. As for the perception of the respondents in classes, a vast proportion of them (83.7\%) in junior classes were of the view that unfriendly attitudes of medical personnel will discourage them from using ARHS while it was $79.8 \%$ of senior classes who held similar view in the studied location. In term of 
Table 6. Relationship between some demographic variables and providers attitude to ARHS.

\begin{tabular}{|c|c|c|c|c|c|}
\hline Variable & $\begin{array}{c}\text { Strongly } \\
\text { Agreed } \\
(\mathrm{N} / \%)\end{array}$ & $\begin{array}{l}\text { Agreed } \\
(\mathrm{N} / \%)\end{array}$ & $\begin{array}{c}\text { Disagreed } \\
(\mathrm{N} / \%)\end{array}$ & $\begin{array}{c}\text { Strongly } \\
\text { Disagreed } \\
(\mathrm{N} / \%)\end{array}$ & $\begin{array}{l}\text { Total } \\
(\mathrm{N} / \%)\end{array}$ \\
\hline \multicolumn{6}{|c|}{ Sex } \\
\hline Male & $36(4.8)$ & $97(12.9)$ & $154(20.5)$ & $465(61.8)$ & $752(100)$ \\
\hline Female & $63(8.8)$ & $72(10.1)$ & $139(19.5)$ & $439(61.6)$ & $713(100)$ \\
\hline \multicolumn{6}{|c|}{ Classes of Students } \\
\hline Junior Sec. Students & $24(3.4)$ & 89 (12.9) & $160(23.0)$ & $423(60.7)$ & $696(100)$ \\
\hline Senior Sec. Students & $75(10.0)$ & $80(10.2)$ & $133(17.0)$ & $481(62.8)$ & $769(100)$ \\
\hline \multicolumn{6}{|c|}{ Age (Year) } \\
\hline $9-11$ & $13(4.1)$ & $43(13.7)$ & $74(23.5)$ & $185(58.7)$ & $315(100)$ \\
\hline $12-14$ & $37(7.0)$ & $58(10.9)$ & $104(19.6)$ & $331(62.5)$ & $530(100)$ \\
\hline $15-17$ & $43(7.8)$ & $58(10.6)$ & 109 (19.9) & $338(61.7)$ & $548(100)$ \\
\hline $18-20$ & $6(8.3)$ & $10(13.9)$ & $6(8.3)$ & $50(69.4)$ & $72(100)$ \\
\hline \multicolumn{6}{|c|}{ Religion } \\
\hline Catholic & $15(6.6)$ & $28(12.4)$ & $47(20.8)$ & $136(60.2)$ & $226(100)$ \\
\hline Protestant & $40(6.5)$ & $69(11.2)$ & $130(21.1)$ & $377(61.2)$ & $616(100)$ \\
\hline Pentecostal & $41(6.9)$ & $71(11.9)$ & $110(18.5)$ & $373(62.7)$ & $595(100)$ \\
\hline Others & $3(10.7)$ & $1(3.6)$ & $6(21.4)$ & $18(64.3)$ & $28(100)$ \\
\hline \multicolumn{6}{|c|}{ Ethnicity } \\
\hline Igbo & $32(7.8)$ & $48(11.7)$ & $96(23.4)$ & $235(57.2)$ & $411(100)$ \\
\hline Isoko & $6(5.1)$ & $15(12.7)$ & $20(16.9)$ & $77(65.3)$ & $118(100)$ \\
\hline Ijaw & $26(6.2)$ & $48(11.5)$ & $78(18.7)$ & $266(63.6)$ & $418(100)$ \\
\hline Urhobo & $35(8.1)$ & $51(11.9)$ & $89(20.7)$ & $255(59.3)$ & $430(100)$ \\
\hline Itsekiri & $0(0.0)$ & $2(10.5)$ & $5(26.3)$ & $12(63.2)$ & $19(100)$ \\
\hline Others & $6(8.7)$ & $8(11.6)$ & $23(33.3)$ & $32(46.4)$ & $69(100)$ \\
\hline \multicolumn{6}{|c|}{ Parents' Highest Level of Education } \\
\hline No schooling & $20(5.4)$ & $46(12.2)$ & $72(19.1)$ & $239(63.3)$ & $377(100)$ \\
\hline $\begin{array}{c}\text { Completed Primary } \\
\text { School }\end{array}$ & $30(6.4)$ & $58(12.4)$ & $106(22.6)$ & $275(58.6)$ & $469(100)$ \\
\hline $\begin{array}{c}\text { Completed Secondary } \\
\text { School }\end{array}$ & $40(8.3)$ & $54(11.1)$ & $86(17.8)$ & $303(62.8)$ & $483(100)$ \\
\hline $\begin{array}{l}\text { Tertiary education } \\
\text { and equivalents }\end{array}$ & $8(5.9)$ & $11(8.1)$ & $30(22.1)$ & $87(63.9)$ & $136(100)$ \\
\hline \multicolumn{6}{|c|}{ Parents' Income } \\
\hline 10,000 or less & $29(6.9)$ & $53(12.6)$ & $83(19.7)$ & $256(60.8)$ & $421(100)$ \\
\hline $11,000-20,000$ & $10(4.9)$ & $20(9.8)$ & $50(24.3)$ & $125(61.0)$ & $205(100)$ \\
\hline $21,000-30,000$ & $8(4.5)$ & $16(8.9)$ & $37(20.7)$ & $118(65.9)$ & $179(100)$ \\
\hline $31,000-40,000$ & $5(8.5)$ & $8(13.6)$ & $12(20.3)$ & $34(57.6)$ & $59(100)$ \\
\hline 41,000 and above & $8(8.8)$ & $8(8.8)$ & $21(23.1)$ & $54(59.3)$ & $91(100)$ \\
\hline \multicolumn{6}{|c|}{ Residence } \\
\hline Rural & $40(5.4)$ & $90(12.4)$ & $166(22.8)$ & $430(59.1)$ & $726(100)$ \\
\hline Urban & $57(7.7)$ & $72(9.7)$ & $167(22.6)$ & $443(59.9)$ & $739(100)$ \\
\hline
\end{tabular}


the age of respondents across all ages, $80.9 \%$ believed that unfriendly attitudes of providers of ARHS will make them not to use services-with persons between the ages of $9-11(82.2 \%)$ holding this view while youth of $18-20$ years least $(77.8 \%)$ in their opinion of being discouraged by unfriendly attitudes of medical providers. The view that medical personnel unfriendly attitudes will discourage adolescents was also overwhelmingly held by religious denominations and ethnic groups since aggregate of religious bodies was $82.6 \%$ compared to $82.3 \%$ of all ethnic groups such as urhobo, Ijaw, Igbo, Itsekiri, Isoko and others who took part in the studies who agreed that unfriendly attitudes of medical personnel will discourage them from accessing and using ARHS. Respondents whose parents have different level of education and income also have a collective proportion of $82.6 \%$ and $82.5 \%$ respectively that unfriendly attitudes of medical personnel will discourage them from using ARHS while at the residential level, both rural (81.9\%) and urban (82.5), it was the opinion of respondents in the studied area that the unfriendly attitudes of medical personnel will discourage them from using ARHS. Hence, it evidence from the above, that irrespective of the demographic or economic attributes used in this study, the attitudes of providers is very important in the access and use of ARHS. Therefore, the success of any program which wants to encourage adolescents' access and usage of reproductive health services, care must be taken to promote healthy and friendly attitudes of providers which make adolescents feel safe to receive the services.

The findings from this study agree with previous studies that providers' attitudes will affect the rate of access and utilization of ARHS. According to the studies, providers with repulsive attitude frequently fail to take seriously youth's need for services and may even try to dissuade young people from having sexual relations. Providers' attitudes according to the studies have to do with the cultures that do not accept sexuality of adolescents and sexuality in general as a natural and positive part of the full development of every person. Such hostile attitudes from the perspectives of the studies may result in young people's giving up-not on having sexual intercourse-but on using contraception and other ARHS [6] [12] [14] [15].

\section{Conclusion}

Poor or unfriendly health providers' attitudes such as keeping adolescent waiting, spending little time with them during consultations, judgmental attitude of providers and lack of confidentiality in service provision are associated with low adolescents' access and use reproductive health services in Delta State irrespective of the sex, age, class, religion, residence, ethnic group, parents' education or income levels. It is important that medical personnel take all these issues very seriously when dealing with adolescents to enhance access and use adolescents' reproductive health services in Delta State and indeed Nigeria.

\section{Limitations}

This study is a perception study relying heavily on what respondents think in 
most instances, and partly on users' experiences. Study dealing entirely on users' experiences of ARHS would reveal greater determinant of lack of access and use as occasioned by providers' attitude. Also, data analyses did not involved gender segregations since no gender differences were noticed for both sexes of adolescents in their outlook to providers' attitude to access and use of reproductive health services. Lastly, the relationship between some demographic variables and providers attitude would have been more apparent if regression analysis was attempted here, but this was not the case with this paper, since the data are being explored for further publication with more rigorous analyses.

\section{Acknowledgements}

This publication as well as the research leading to the publication was sponsored by the Think Tank Initiative (TTI) of IDRC, Canada and Centre for Populations and Environmental Development Benin City, Nigeria.

\section{References}

[1] Françoise, F. (1999) Cairo + Five: Reviewing Progress for Women Five Years after the International Conference on Population and Development. Journal of Women's Health and Law, 1, 158-169.

[2] Potard, C., Courtois, R., Samedy, M.L., Mestre, B., Barakat, M.J. and Réveillère, C. (2012) Determinants of the Intention to Use Condoms in a Sample of French Adolescents. The European Journal of Contraception and Reproductive Health Care, 17, 55-64. https://doi.org/10.3109/13625187.2011.634455

[3] Brener, N.D. and Collins, J.L. (1998) Co-Occurrence of Health-Risk Behaviors among Adolescents in the United States. Journal of Adolescents Health, 22, 209-213. https://doi.org/10.1016/S1054-139X(97)00161-4

[4] Lindberg, L.D., Boggess, S. and Williams, S. (2000) Multiple Threats: The Co-Occurrence of Teen Health Risk Behaviors. 7 Urban Institute, Washington DC.

[5] UNAIDS, WHO and UNICEF (2011) Global HIV/AIDS Response: Epidemic Update and Health Sector Progress towards Universal Access. Progress Report.

[6] Brown, S. and Guthrie, K. (2010) Why Don't Teenagers Use Contraception: A Qualitative Interview Study. The European Journal of Contraception and Reproductive Health Care, 15, 197-204. https://doi.org/10.3109/13625181003763456

[7] Fawole, B. (2011) Overview of Current Adolescent Sexual and Reproductive Health and Rights Statistics in Nigeria and Identifying Gaps. In: Okonofua, F.E. and Imade, R., Eds., Identifying Priorities for Research and Documentation on Adolescent Sexual Reproductive Health in Nigeria, Women Health and Action Research Center, Benin, 12-26.

[8] Senderowitz, J. (1999) Making Reproductive Health Services Youth Friendly. Focus on Young Adults. Research Program and Policy Series, Washington DC.

[9] Kamau, A.W. (2006) Factors Influencing Access and Utilization of Reproductive Health Services by Adolescents in Kenya: A Case Study of Murang'a District. Ph.D. Dissertation, University of Bielefeld, Germany.

[10] Kanthiti, F.J. (2007) Factors That Facilitate Adolescent Use of Family Planning Services: A Review of Studies. M.PH Thesis, University of Malawi, Malawi.

[11] Tafuri, S., Martinelli, D., Germinario, C. and Prato, R. (2010) Determining Factors for Condom Use: A Survey of Young Italian Adults. The European Journal of Con- 
traception and Reproductive Health Care, 15, 24-30.

https://doi.org/10.3109/13625180903427683

[12] Zhang, L.Y., Jejeebhoy, S., Shah, I.H., Zhang, L.H., Hsia, J. and Im-em, W. (2004) Contraceptive Services among Unmarried Young People in the North-East of China. The European Journal of Contraception and Reproductive Health Care, 9, 147154. https://doi.org/10.1080/13625180400007181

[13] Lawrence, R.S., Gootman, J.A. and Sim, L.J. (2009) Adolescent Health Services: Missing Opportunities. The National Academies Press, Washington DC.

[14] Moya, C. (2001) Improving Youth's Access to Contraception in Latin America. Advocate for Youth, Washington DC.

[15] Ralpha, L.J. and Brindisa, C.D. (2010) Access to Reproductive Healthcare for Adolescents: Establishing Healthy Behaviors at a Critical Juncture in the Life Course. Adolescent and Pediatric Gynecology, 22, 369-374.

[16] Darroch, J.E., Frost, J.J. and Singh, S. (2001) Teenage Sexual and Reproductive Behavior in Developed Countries: Can More Progress Be Made? Occasional Report, No. 3, AGI, New York.

[17] Darroch, J.E. and Singh, S. (1999) Why Is Teenage Pregnancy Declining? The Roles of Abstinence, Sexual Activity, and Contraceptive Use. Occasional Report No. 1, The Alan Guttmacher Institute (AGI), New York.

[18] Finer, L.B. and Zabin, L.S. (1998) Does the Timing of the First Family Planning Visit Still Matter? Family Planning Perspectives, 30, 30-33+42.

https://doi.org/10.2307/2991523

[19] Hock-Long, L. Herceg-Baron, R. and Cassidy, A.M. (2003) Access to Adolescent Reproductive Health Services: Financial and Structural Barriers to Care. Perspectives on Sexual and Reproductive Health, 35, 144-147.

[20] Brandis, C. and Ott, M.A. (2002) Adolescents, Health Policy, and the American Political Process. Journal of Adolescent Health, 30, 9-16.

[21] Reddy, D.M., Fleming, R. and Swain, C. (2002) Effect of Mandatory Parental Notification on Adolescent Girls' Use of Sexual Health Services. Journal of the American Medical Association, 288, 710-714. https://doi.org/10.1001/jama.288.6.710

[22] Rosen, J.E., Murray, N.J. and Moreland, S. (2004) Sexuality Education in Schools: The International Experience and Implications for Nigeria. Policy Working Paper, No. 12, USAID, Abuja.

[23] Jejeebhoy, S.J., Shah, I.H. and Yount, K.M. (1999) Sexual and Reproductive Health of Adolescents. Annual Technical Report, 91-104.

[24] Guttmacher Institute (2010) Minors' Access to Contraceptive Services, State Policies in Brief. http://www.guttmacher.org/statecenter/spibs/spib_MACS.pdf

[25] Berkat, A. and Murtaza, M. (2003) Adolescent Reproductive Health in Bangladesh. Status, Policies, Programs and Issues. Policy Project, USAID, Abuja.

[26] Delta State Ministry of Education (2006) State of Education in Delta State (A Report). Ministry of Basic Education, Asaba.

[27] Ofo, J.E. (1994) Research Methods and Statistics in Education and Social Sciences. Joja Educational Research and Publishers limited, Lagos.

[28] Neuman, W.L. and Robson, K. (2009) Basics of Social Research, Qualitative and Quantitative Approaches. Pearson Education, Toronto.

[29] Sandelowski, M. (2000) Focus on Research Methods: Whatever Happened to Qualitative Research. Research in Nursing and Health, 23, 334-340.

https://doi.org/10.1002/1098-240X(200008)23:4<334::AID-NUR9>3.0.CO;2-G 
[30] Conrad, P. (2003) Qualitative Health Research. International Encyclopaedia of the Social and Behavioural Sciences. Elsevier Science Ltd., Amsterdam, 6608-6612.

[31] Marshall, C. and Rossmann, G. (1995) Designing Qualitative Research. 2nd Edition, Sage Publications Inc., California.

[32] Adelman, H.S., Barker, L.A. and Nelson, P. A. (1993) Study of School-Based Clinics: Who Uses It and Who Doesn't. Journal of Clinical Child Psychology, 22, 52-59. https://doi.org/10.1207/s15374424jccp2201_5

[33] Coyne-Beasley, T., Ford, C.A., Martha, W., Waller, M.A., Adimora, A.A. and Resnick, M.D. (2003) Sexually Active Students' Willingness to Use School-Based Health Centers for Reproductive Health Care Services in North Carolina. Ambulatory Pediatrics, 3, 196-202.

[34] Pastore, D.R., Juszczak, L., Fisher, M.M. and Friedman, S.B. (1998) School Based Health Center Utilization: A Survey of Users and Nonusers. Archives of Pediatrics and Adolescent Medicine, 152, 763-767. https://doi.org/10.1001/archpedi.152.8.763

[35] Millstein, S.G. (1993) Adolescents' Health Promotion: Rationale, Goals, and Objectives. In: Millstein, G.S., Petersen, A.C. and Nightingale, E.O., Eds., Promoting the Health of Adolescents: New Directions for the Twenty-First Century, Wiley, Hoboken, 199-216.

[36] Isiugo-Abanihe, U. (2011) Adolescents' Sexuality and Sexual Behavior: What We Know and Do Not Know. In: Okonofua, F.E. and Imade, R., Eds., Identifying Priorities for Research and Documentation on Adolescent Sexual Reproductive Health in Nigeria, Women Health and Action Research Center, Benin, 27-37.

\section{Submit or recommend next manuscript to SCIRP and we will provide best service for you:}

Accepting pre-submission inquiries through Email, Facebook, LinkedIn, Twitter, etc. A wide selection of journals (inclusive of 9 subjects, more than 200 journals) Providing 24-hour high-quality service User-friendly online submission system Fair and swift peer-review system Efficient typesetting and proofreading procedure Display of the result of downloads and visits, as well as the number of cited articles Maximum dissemination of your research work

Submit your manuscript at: http://papersubmission.scirp.org/ Or contact health@scirp.org 